\title{
GEOGRAPHICAL INFORMATION SYSTEM (GIS) FOR WATER RESOURCES MANAGEMENT
}

\author{
Nagraj S. Patil ${ }^{1}$, A. K. Gosain ${ }^{2}$ \\ ${ }^{1}$ Associate Professor, Civil Engineering Department, SDM College of Engg, \& Tech. Dharwad \\ ${ }^{2}$ Professor, Civil Engineering Department, IIT Delhi, New Delhi \\ nagrajspatil@yahoo.com
}

\begin{abstract}
Water resources projects are inherited with overlapping and at times conflicting objectives. These projects are often of varied sizes ranging from major projects with command areas of millions of hectares to very small projects implemented at the local level. Thus, in all these projects there is seldom proper coordination which is essential for ensuring collective sustainability.

Integrated watershed development and management is the accepted answer but in turn requires a comprehensive framework that can enable planning process involving all the stakeholders at different levels and scales is compulsory. Such a unified hydrological framework is essential to evaluate the cause and effect of all the proposed actions within the drainage basins.

The present paper describes a hydrological framework developed in the form of a Hydrologic Information System (HIS) which is intended to meet the specific information needs of the various line departments of a typical State connected with water related aspects. The HIS consist of a hydrologic information database coupled with tools for collating primary and secondary data and tools for analyzing and visualizing the data and information. The HIS also incorporates hydrological model base for indirect assessment of various entities of water balance in space and time. The framework would be maintained and updated to reflect fully the most accurate ground truth data and the infrastructure requirements for planning and management.
\end{abstract}

Keywords: Hydrological Information System (HIS); WebGIS; Data Model; Web Mapping Services

\section{INTRODUCTION}

Integrated water resource management planning is a comprehensive planning process, involving all stakeholders within the drainage system, who together as a group, cooperatively work towards identifying the water resource issues and concerns, as well as developing and implementing plans with solutions that are environmentally, socially and economically sustainable at various levels of connectivity of the drainage system.

It is important to understand that integrated water resource management should not merely imply the maintenance of an inventory of different activities to be undertaken within a hydrological unit. It also requires the collation of relevant information needed to evaluate the cause and effect of all the proposed actions within the drainage basin. The watershed is the smallest unit where the evaluation of man induced impacts upon natural resources becomes possible.

Since a watershed is considered as the smallest unit of a drainage basin, a hydrological framework that can keep track of the inter-connection of these units is essential. The impact resulting from action taken at the watershed level will be experienced at a higher level within the drainage basin, and the assessment of these impacts will require the availability of the framework. Such a framework will require regular maintenance and updating to reflect fully the most accurate ground truth data and the infrastructure requirements for planning and management of the relevant planning departments. Such a framework, once available, could be used by all the line departments and updated by the relevant departments which have designated jurisdiction over the data entry.

The development of Hydrologic Information System component is logical response to meet the specific information technology needs of the various line departments. A hydrologic information system consists of a hydrologic information database coupled with tools for acquiring data to fill the database and tools for analyzing, visualizing and modeling the data contained within it.

This GIS portal (http://gisserver.civil.iitd.ac.in), for the general user, exposes Web Mapping Application for accessing Hydrological Information and Web based Interface applications based on the SWAT Modeling. 


\section{MAJOR ELEMENTS OF THE FRAMEWORK}

The steps taken in the development of framework for water resource information system include: 1.Geodatabase Design and Implementation 2. Generationof indirect information through simulation3. Dissemination of information through GIS server

The common framework for water resources planning and management requires creation of base layers at different scales so as to cater to the relevant problems at the respective scales. However, it is imperative that all these scales should merge through the GIS environment for aggregation and integration to be possible. It is intended to provide this framework at the State level and with implementation at various departments connected with water resources. The major elements of the framework include as show in the figure 1

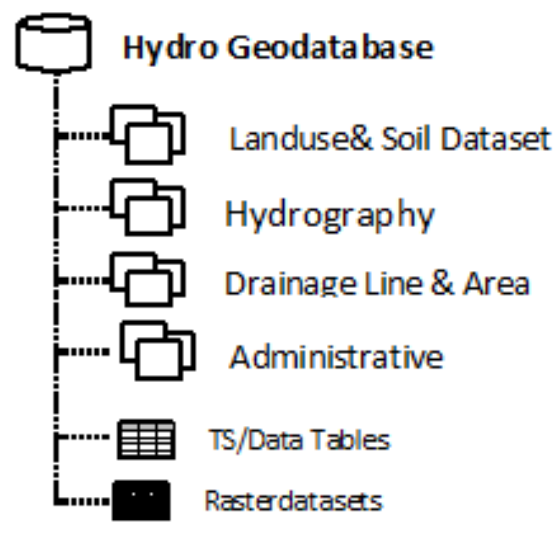

Fig.1 Framework of Hydro Geodatabase

Arc Hydro data model could only meet the basic information[6][7]. The Geodatabase was extended to capture the information related to administrative area, Landuse, soil feature class and non spatial data related to socio-economic.

Hydrography Dataset was also further extended to capture some of the feature class like Dam, Canal, Water Body,Borewell, Hydro Projects, Irrigation Scheme, Water Supply Scheme, Sewage Treatment Plant, Industry, Rain gauge and Monitoring Point.Dam feature class is related with nonspatial data like Area Capacity, Water utilization, Sesimacity of Area, Reservoir (static data), Reservoir Water level, Power Projects. Canal feature class is related with non-spatial data like Canal Dimension and Discharge. Borewell feature class is related with non-spatial data like Discharge, Groundwater Table and Water Quality Parameter. Sewage treatment plant feature class is related with non-spatial data like sewagetreatment plant discharge. Water treatment plant feature class is related Water Quality Parameters and Pump Station.
Drainage Line and Area Dataset consist of Basin,Catchment, Sub-Catchment, Watershed and drainage line. Administrative Dataset consist of feature class like State, District, Tehsil, and Village. Landuse and Soil dataset contains Landuse and Soil feature class.

Other non-spatial data like Demography, Livestock data are collected from village and aggregated up to district level. Irrigated Area, Agriculture Area, Crop, Fertilizer, and Pesticide data are collected at the district level.

\section{GIS SERVER}

In different line departments it is a real challenge to minimize redundancy while ensuring that the right data is accessible in a timely and efficient manner. With hundreds of remote offices and thousands of internal and external GIS users at different levels of expertise and needs, it is important to overcome multiple barriers while designing enterprise GIS [9].

One solution is to implement a server-based GIS that could cope with all the above desired attributes[10]. The aggregation of information should be done at central place by placing a GIS server and database server for the purpose. Server-based GIS can be defined as centrally hosted GIS computing. Internal GIS capabilities are shared with users in the department network while a Web-based platform is also maintained for external users.[11] GIS users are connected to the central GIS servers using desktop GIS software, Web browsers, and custom applications as depicted in Figure 2.

\section{WEB INTERFACE FOR WATER RESOUCES APPLICATIONS}

In the present study the Hydro Geodatabase has been implemented on Himachal Pradesh state as a case. The principal departments that are responsible for water resources development in Himachal Pradesh for various purposes are the Irrigation and Public Health Department (IPH), Agriculture Department, Rural Development Department (RD), Forest Department (FD).

A wide range of applications relevant for the planning and management of water resources is demonstrated using this framework built at the macro level as well as some patches developed at the larger scales. This web portal can be accessed by the request of the URL http://gisserver.civil.iitd.ac.in

\subsection{IPH Department}

As part of the demonstration, information from the IPH department pertaining to their activities was incorporated in the Web based GIS portal. The figure 3 shows Web based Mapping Application on the irrigation schemes being operated by IPH department in respective village. It shows the Watershed boundary, drainage line, Irrigation scheme location 
feature class are overlaid over village boundary. By using identify button on the Irrigation scheme location, along with the attribute data of this feature class, it possible to obtain the attribute data of all the feature class below it. This helps the user to get the detail information about the irrigation scheme, on which watershed the scheme is operating and the beneficiary village with population. Similarly many such applications can be demonstrated using this frame work

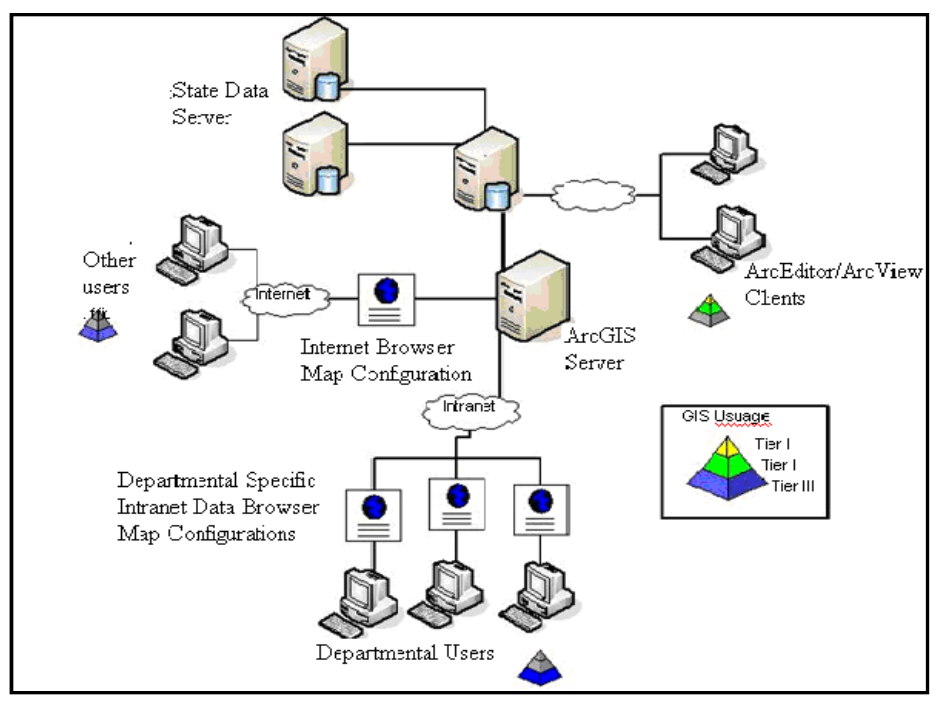

Fig.2 Enterprise Wide Application Configuration

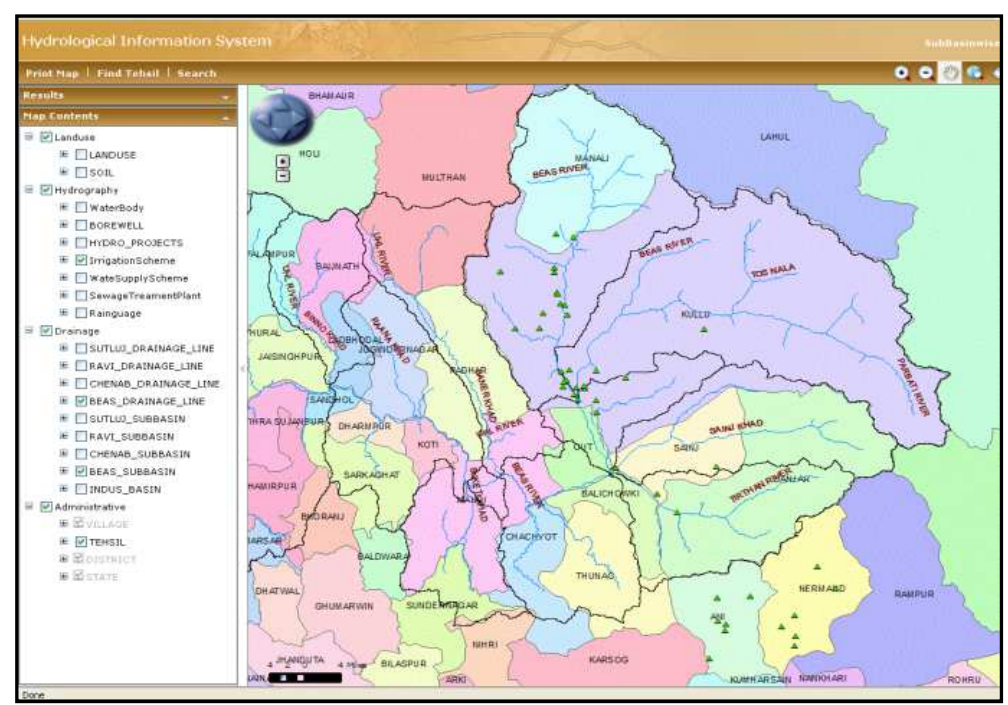

Fig. 3 Information of the Irrigation Schemes operated in the state by IPH

\section{MODEL BASE TO HYDRO GEODATABASE}

Arc Hydro data model structure could not support the SWAT model output which was essential for the present study. The Arc Hydro data model was further extended to support SWAT model output. The details of this development are out of scope of this paper.

\subsection{SWAT Model}

The Soil and Water Assessment tool (SWAT) [2] is a continuous-time, spatially distributed simulator of water, sediment, nutrients and pesticides transport at a catchment scale. It runs on a daily time step. In SWAT, a basin is divided into a number of watersheds. Within each watershed, Soil and Landuse maps are overlaid to create a number of unique 
hydrologic response units(HRUs). SWAT simulates surface and subsurface processes, accounting for snow fall and snow melt, vadose zone processes (i.e., infiltration, evaporation, plant uptake, lateral flows and percolation into aquifer). Runoff volume is calculated using the Curve Number method. Sediment yield from each sub-basin is generated using the Modified Universal Soil Loss Equation (MUSLE) [13]. The model updates the $\mathrm{C}$ factor of the MUSLE on a daily basis using information from the crop growth module. The routing phase controls the movement of water using the variable storage method or the Muskingum method[3],[4].

\section{CASE STUDY}

Indus River in north India is selected for the present study. The model set-up and runs were performed using SWAT hydrological model. The GIS interface of this model ArcSWAT provides an excellent platform for data management and result analysis. In the present study, two futuristic climate scenarios A2 and B2, and one baseline scenario BL has been used to address the uncertainty issues. Regional scale datasets used for model set-up were: land-use from global land cover fraction, soil from FAO and terrain model from SRTM.Primarily the water yield and evapotranspiration component of water balance were modeled for each of the sub-catchment. The modeled flow at the subcatchment outlets were also evaluated for the various scenarios. To induce a level of confidence in the generated results, the basin was modeled using Indian Meteorological Department (IMD) gridded precipitation and temperature datasets. A good comparison was found between the baseline scenario (BL) results and observed dataset (IMD) results. This investigation would provide a good basis for selecting appropriate adaptation strategies to cater to the climate change impacts.

SWAT model version 2.1.3 is run on the desktop system, using the ArcGIS interface and the model results of Subbasin; Reach for monthly and daily time step was imported to Hydrological Information System (HIS) Geodatabase.

\section{WEB BASE GIS INTERFACE FOR ANALYSIS OF MODEL RESULTS}

The web based Interface starts by the request of the $U R L$ http://gisserver.civil.iitd.ac.in/natcom. This interface was developed for viewing the model results of the respective SubCatchment. Figure 4 shows the user view of Indus basin. The user can zoom in further to view the catchment, sub-catchment and to the watershed level. The standardization of this drainage area was done by giving the unique identification number at different levels. These unique identification number along with sub-catchment name where used as reference for further analysis. Figure 5 shows the Web Mapping services of sub-catchment with unique identification number as their labels.

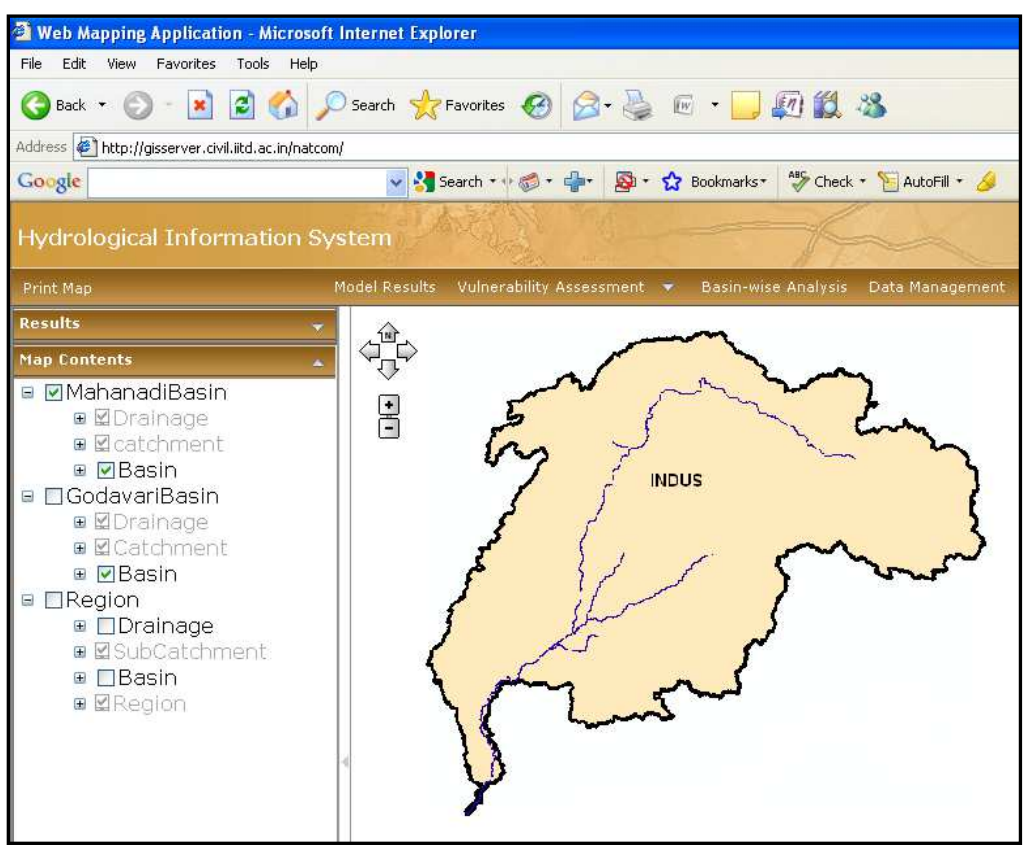

Fig. 4 User view of Indus basin 


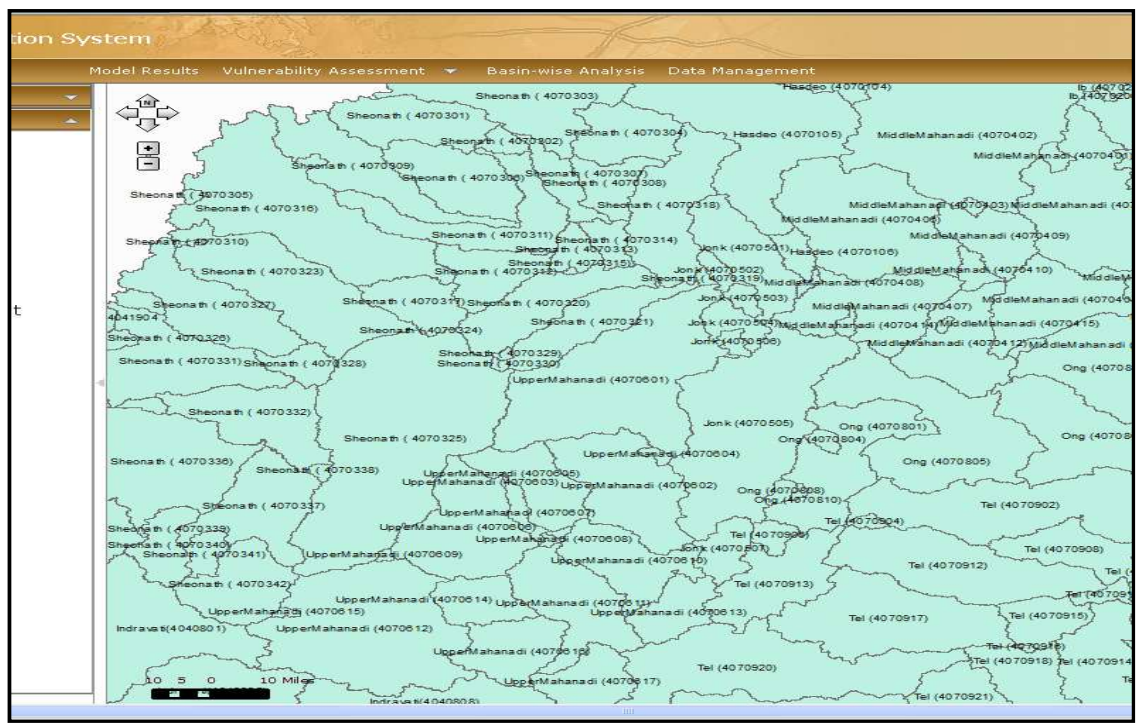

Fig.5 User view of Sub-Catchment with unique identification number as their labels

Figure 6 shows the web based interface to analysis the model results. With this web based interface the user is given the option of analysis the Catchment or Sub-Catchment or Watershed by selecting it respectively, by selecting the radio button side to it confirms the respective selection. The user is also given the option to select the analysis of the SWAT model results with the different data set like India Meteorological Department (IMD) for the period of 1971 to 2005. HadRM3 baseline Scenario (BL) for the period 1961 to 1990, HadRM3 GHG Scenario A2 \& B2 for the period 2071 to 2100 . It is important to assess the behaviour of the drainage area with and without man made intervention, so the web based interface is also designed with this concern. SWAT model gives many outputs parameters but only few parameters like Water Balance components, Flow, Water Quality parameters like Nitrite, Nitrate, Ammonium, Organic Nitrogen, Organic Phosphorus, Mineral Phosphorus, CBOD and Dissolved Oxygen, are given as option to user for analysis. The user is also given the option for the selecting the time during for the analysis. The selected parameters can be viewed through graphs or tables. This web based interface provides a robust frame platform for the assessing the status of water resources.

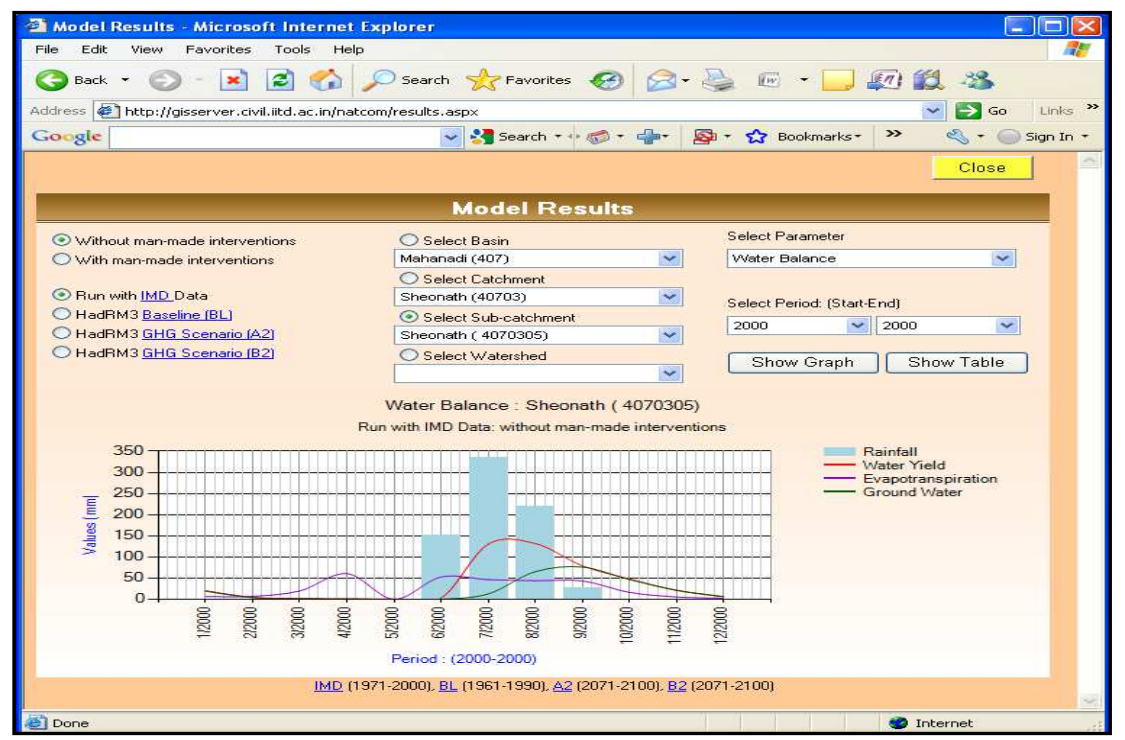

Fig.6 Web Based interface to analysis the model results 


\section{CONCLUSIONS}

The development of a Geospatial Web Portal is proposed as the best solution to Hydrological Information and Data Management. The Web Portal built around a hydrological data model synthesizes data from diverse sources describing the water resource, provides visualization tools and link to externally modeled results. This Geospatial Web Portal would provide a robust platform for the planning, execution and monitoring of status of water resources.

\section{REFERENCES}

[1]. M.B. Abbott andA.W.Minns (1998), "Computational hydraulics" ( $2^{\text {nd }}$ Ed.), AshgatePress,Aldershot, 557p.

[2]. J.G.Arnold R.Srinivasan, R.S.Muttiah, J.R.Williams 1998. Large area hydrologic modeling and assessment- Part 1: Model development. Journal of the American Water Resources Association 34(1),73-89.

[3]. V.T. Chow,D.R. Maidment,L.W.Mays (1988). Applied Hydrology. McGraw-Hill, New Delhi4. J.A.York Cunge(1969). On the subject of a flood propagation method (Muskingum Method). Journal of Hydraulics Research 7(2), 205-230.

[4]. J.A.Cunge(1969). On the subject of a flood propagation method (Muskingum Method).Journal of Hydraulics Research 7(2), 205-230.

[5]. W.G.Gray, ,A.Leijnse, R.L.Kollar. C.A. Blain (1993), "Mathematical tools for changing spatial scales in the analysis of physical system." CRC Press, Boca Raton, FL,232p.

[6]. D.R. Maidment(2002) Arc Hydro: GIS for Water Resources, ESRI Press, Redlands, Calif 203 pp.[7]. Mehdi Mashud Khan, Angela Kneece, IshwariSivagnanam, Jared John Shoultz(2009).

http://www.esri.com/news/arcuser/0507/dhec.html (accessed January 17, 2013)

[8]. R.J. Naiman and R.E. Bilby (1998), (ed.) "River Ecology and Ma nagement", Springer, New York, 705p.

[9]. G.F.Pinder(2002), "Groundwater Modeling using geographical information systems", Wiley, New York, 231pp.

[10[. Spotsylvania County Government (2008). "Spotsylvania County Enterprise-Wide Applications" https://www.spotsylvania.va.us/emplibrary/Enterpriseide_Solutions.pdf (accessed May 22,2013)

[11]. D.A.Quattrochi and M.F. Goodchild (1997), "Scale and remote sensing in GIS", Lewis Publishers, Boca Raton, FI.

[12]. J.P.WilsonandJ.C.Gallant (2000), "Terrain analysis, principles and applications" Wiley, New York, 479p.

[13]. J.R.Williams(1995). The EPIC model. In: Singh, V.P.(Ed.), Computer Models of watershed Hydrology. Water Resources Publication, Colorado, USA, pp.909-1000 